\title{
Is It Necessary to Apply Neuroprotective Methods after Cardiac Arrest?
}

\author{
Calixto Machado ${ }^{1}$ Gerry Leisman ${ }^{2,3, \odot}$ \\ ${ }^{1}$ Department of Clinical Neurophysiology, Institute of Neurology \\ and Neurosurgery, Havana, Cuba \\ ${ }^{2}$ Faculty of Social Welfare and Health Sciences, University of Haifa, \\ Israel \\ ${ }^{3}$ Department of Neurology, University of the Medical Sciences, \\ Havana, Cuba
}

J Card Crit Care:2020;4:163-164

\begin{abstract}
Address for correspondence Gerry Leisman, MD, PhD, Faculty of Social Welfare and Health Sciences, University of Haifa, Abba Khoushy Ave. 199, Eshkol Tower, Rm. 910, Mt. Carmel, Haifa 3498838, Israel (e-mail: g.leisman@edu.haifa.ac.il).
\end{abstract}
Abstract
Keywords
- brain death
- cardiac arrest
- cardiopulmonary resuscitation
- neuroprotection

In effectively resuscitated out-of-hospital cardiac arrest (OHCA) patients who progress to brain death $(B D)$, resuscitated OHCA with predominantly nonshockable initial rhythms was independently associated with the following five risk factors associated with progression toward BD: female gender, young age, neurologic cause of cardiac arrest, duration of low-flow period, and persistent hemodynamic shock, all of which were independently associated with $\mathrm{BD}$. We require employment of neuroprotection methods to those cases suffering from OHCA, or even from intrahospital cardiac arrests, based on the examination of prognostic risk factors.
To the Editor,

Cour et al ${ }^{1,2}$ have analyzed risk factors in patients effectively resuscitated out-of-hospital cardiac arrest (OHCA) who progress to brain death (BD). Their study found that in those cases, resuscitated OHCA with predominantly nonshockable initial rhythms was independently associated with the following five simple risk factors associated with progression toward $\mathrm{BD}$ : female gender, young age, neurologic cause of cardiac arrest, duration of low-flow period, and persistent hemodynamic shock. These were independently associated with BD. The authors concluded that these factors might assist in the early recognition of a probable pool of future organ donors. ${ }^{3}$ Nonetheless, we require employment of neuroprotection methods to those cases suffering from OHCA or even from intrahospital cardiac arrests. ${ }^{3}$

Hypothermia is the best-known method to protect the brain and bodily organs against the effects ischemia and anoxia.4 The advantage of hypothermia treatment has also been supported by reports of patients suffering from accidental hypothermia (e.g., immersion/submersion in cold water, snow avalanche, or prolonged exposure to cold surroundings) combined with circulatory arrest or severe circulatory failure during long periods of time. When these patients were rewarmed to normothermia by use of extracorporeal circulation, good outcome in several cases has been reported. ${ }^{5,6}$ The key point in these cases is that the neuroprotective effect occurred early, before a complete cardiac arrest had occurred.

Our commentary concerns the effects of hypoxia and ischemia on the brain after cardiac arrest. The human brain uses approximately $20 \%$ of the cardiac cycle, allowing cerebral blood flow (CBF) to be tightly regulated to meet the brain's metabolic demands. The CBF dropping to less than $20 \mathrm{~mL} / 100 \mathrm{gm} / \mathrm{min}-$ ute produces ischemic neuronal activity reduction but still reversible neuronal changes. $\mathrm{CBF}$ values less than $10 \mathrm{~mL} / 100$ $\mathrm{gm} /$ minute result in irreversible ischemic neuronal damage within minutes, as reflected by membrane failure. ${ }^{7}$ That's why the $\mathrm{CBF}$ values between 10 and $20 \mathrm{~mL} / 100 \mathrm{gm} /$ minute are considered the ischemic penumbra, reflecting neuronal tissue that may potentially be rescued. $3,7,8$

Even when resuscitation in cardiac arrest is successful, recovery is too often limited by anoxic encephalopathy. This complication increases with delay in resuscitation, and then the prognosis for comatose survivors of cardiac arrest is frequently poor. ${ }^{3}$ published online

October 18, 2020
DOI https://doi.org/

10.1055/s-0040-1718984

ISSN 2457-0206.
(C) 2020. Official Publication of The Simulation Society (TSS), accredited by International Society of Cardiovascular Ultrasound (ISCU).

This is an open access article published by Thieme under the terms of the Creative Commons Attribution-NonDerivative-NonCommercial-License, permitting copying and reproduction so long as the original work is given appropriate credit. Contents may not be used for commercial purposes, or adapted, remixed, transformed or built upon. (https://creativecommons.org/licenses/by-nc-nd/4.0/)

Thieme Medical and Scientific Publishers Pvt. Ltd., A-12, 2nd Floor, Sector 2, Noida-201301 UP, India 
Several research groups have developed protocols for lowering body temperature in comatose survivors of cardiac arrest, resulting in a significant improvement in neurologic outcome. Safar ${ }^{8}$ documented in dog experimental models of prolonged exsanguination brain and organ preservation during cardiac arrest (no-flow) durations for up to 120 minutes. They noted that it is logical for mild hypothermia to be used in focal ischemic insults such as stroke, where it could play a neuroprotective role, but noted that reperfusion was critical in that condition, and hypothermia should serve as a bridge and/or adjunct in that regard. They stated that the plumbing must be addressed in stroke, otherwise acute therapies cannot be effective. ${ }^{9}$

Risk factors aiding clinicians in the prognosis of patients after OHCA are quite simple to determine. 1 It is necessary to develop and apply neuroprotective methods to prevent brain damage due to anoxia and ischemia, initiated as soon as possible after cardiac arrest and maintained even during cardiopulmonary resuscitation. ${ }^{3}$

\section{Conflict of Interest}

None declared.

\section{Author Contribution}

Calixto Machado contributed to the conceptualization, writing, and original draft preparation, and Gerry Leisman contributed to the conceptualization, writing, and original draft preparation, reviewing, and editing.

\section{References}

1 Cour M, Turc J, Madelaine T, Argaud L. Risk factors for progression toward brain death after out-of-hospital cardiac arrest. Ann Intensive Care 2019;9(1):45

2 Dumas F, White L, Stubbs BA, Cariou A, Rea TD. Long-term prognosis following resuscitation from out of hospital cardiac arrest: role of percutaneous coronary intervention and therapeutic hypothermia. J Am Coll Cardiol 2012;60(1):21-27

3 Machado $C$. The brain is the target organ in cardiorespiratory reanimation. Curr Anaesth Crit Care 2009;20:148

4 Mwaura L, Rubino A, Vuylsteke A. No cold death-extracorporeal life support for all victims of accidental hypothermia. J Cardiothorac Vasc Anesth 2020;34(2):372-373

5 Wanscher M, Agersnap L, Ravn J, et al. Outcome of accidental hypothermia with or without circulatory arrest: experience from the Danish Præstø Fjord boating accident. Resuscitation 2012;83(9):1078-1084

6 Haggerty M, Herrick H, Ades A. Post-cardiac arrest care in the neonatal intensive care unit. Resuscitation 2020;150:102-103

7 Jordan KG. Neurophysiologic monitoring in the neuroscience intensive care unit. Neurol Clin 1995;13(3):579-626

8 Safar P. Mild hypothermia in resuscitation: a historical perspective. Ann Emerg Med 2003;41(6):887-888, author reply 888

9 Kochanek PM, Drabek T, Tisherman SAT. Therapeutic hypothermia: the Safar vision. J Neurotrauma 2009;26(3):417-420 